\title{
Studies of the Function and Structure of In Vitro Propagated Human Granulocytes
}

\author{
ROBERT W. FRENCK, GERARD J. VENTURA, GENA KRANNIG, EDWARD A. FELIX, \\ THEODORE F. ZIPF, W. BARRY VANWINKLE, AND E. STEPHEN BUESCHER \\ Department of Pediatrics, University of Texas Medical School at Houston [R.W.F., E.S.B.], Departments of \\ Internal Medicine [G.J.V.] and Experimental Pediatrics [E.A.F., T.F.Z.], M.D. Anderson Cancer Center and the \\ Cryobiology Research Center [G.K., W.B.V.], University of Texas Health Science Center at Houston, \\ Houston, Texas 77030
}

\begin{abstract}
In our study, hematopoietic progenitor cells isolated from human umbilical cord blood were grown in an in vitro liquid culture system using the recombinant colony stimulating factors IL-3 plus granulocyte-macrophage colony-stimulatory factor (GM-CSF) or IL-3 plus granulocyte colony stimulating factor (G-CSF). The morphology and function of the cells produced were then studied, and it was demonstrated that continuous exposure to IL-3 plus GM-CSF produced predominantly eosinophilic granulocytes, whereas IL-3 plus G-CSF produced neutrophilic granulocytes. Cells from IL-3/GM-CSF cultures showed progressively increasing oxygen metabolism and locomotive capabilities over time, which became equivalent to peripheral blood neutrophils at wk 4 and 3 , respectively. Phagocytic activity of these cells was poor. IL3/G-CSF cultures produced cells with progressive increases in oxygen metabolism, locomotion, and phagocytosis. These functions never became equivalent to those of peripheral blood neutrophils. Flow cytometric analysis of IL-3/G grown cells showed that they expressed CD11b on their surfaces and that surface expression increased 2 -fold after secondary granule secretagogue exposure. Ultrastructurally, the eosinophilic granulocyte nature of the IL-3/ GM grown cells was confirmed by immunogold-lectin staining and IL-3/G grown cells were shown to contain antigenic myeloperoxidase. The data demonstrate that human umbilical cord blood mononuclear cells can be used to propagate granulocytes in vitro, that the types of granulocytes produced in this culture system depend on the growth factors used, that the cells produced in vitro develop several of the functional characteristics of peripheral blood granulocytes, and that ultrastructural details of developing human granulocytes can be carefully examined in this model system. (Pediatr Res 30: 135-140, 1991)
\end{abstract}

\section{Abbreviations}

CSF, colony stimulating factor

GM-CSF, granulocyte-macrophage colony-stimulating factor

G-CSF, granulocyte colony stimulating factor

EOS, eosinophilic granulocyte

PMN, neutrophilic granulocyte

AcS, activated serum

fMLP, f-met-leu-phe

NBT, nitroblue tetrazolium

PMA, phorbol myristate acetate

Received July 6, 1990; accepted March 28, 1991.

Correspondence: E. S. Buescher, M.D., University of Texas Medical School at Houston, 6431 Fannin Street, Room 1.739, Houston, TX 77030.

Supported by NICHHD Grant No. 2 PO1 HD-13021-09.
Human blood polymorphonuclear granulocytes, including PMN, EOS, and basophilic granulocytes, all arise from common multipotent myeloid progenitor cells. In normal adults, the vast majority of myeloid progenitor cells reside in the bone marrow with only small numbers present in the peripheral blood $(\leq 10 /$ $\mathrm{mL}$ ). However, in human umbilical cord blood and in the peripheral blood of the newborn infant, between $10^{3}$ and $10^{4}$ of these cells can be recovered per $\mathrm{mL}$ of blood, an amount approximating the number of myeloid progenitor cells present in human adult marrow $(1,2)$. In vitro studies have reported that cord blood progenitors will proliferate and differentiate into erythroid burst-forming unit, granulocyte-macrophage, and multipotential colonies after exposure to various hematopoietic CSF (2). No previous reports have examined the function or ultrastructure of the cells grown in this way. In the present study, an in vitro liquid culture system and recombinant CSF were used to propagate PMN and EOS from human umbilical cord blood progenitors. The functional and ultrastructural characteristics of these propagated cells were then compared with those of peripheral blood PMN.

\section{MATERIALS AND METHODS}

Blood Specimen Acquisition. Cord blood specimens were obtained aseptically by two methods. Either blood was drawn by venipuncture directly from the severed, placenta-associated end of the umbilical cord at the time of birth of normal newborn infants or blood was obtained by venipuncture of the placental vessels up to $30 \mathrm{~min}$ after delivery of the placenta. All cord blood specimens were then immediately heparinized and cells were purified from these specimens within $48 \mathrm{~h}$.

Heparinized adult donor blood specimens were obtained aseptically by venipuncture, and cells were purified within $1 \mathrm{~h}$.

Cell Purification. Cord blood specimens were diluted 1:2 with sterile PBS, and the mononuclear cells purified by HypaqueFicoll gradient centrifugation (3). If the mononuclear cell fractions were contaminated with large numbers of erythrocytes, one to two cycles of hypotonic lysis were used to remove the erythrocytes. Cells were then resuspended in sterile PBS and washed twice $(10 \mathrm{~min}, 150 \times g)$ to remove contaminating platelets. PMN from adult control donor blood specimens were purified by the same Hypaque-Ficoll/dextran sedimentation/hypotonic lysis methods.

In Vitro Culture Conditions. The platelet-poor mononuclear cell fraction obtained from each cord blood specimen was washed once and resuspended in AIM V media (Life Technologies Inc., Grand Island, NY) at approximately 5 to $8 \times 10^{6}$ cells $/ \mathrm{mL}$. The mononuclear cell fraction was then transferred to a $150-\mathrm{cm}^{2}$ tissue culture flask and allowed to adhere at $37^{\circ} \mathrm{C}, 5 \% \mathrm{CO}_{2}$ for 4 to $18 \mathrm{~h}$. As previously reported (4), the nonadherent cells were then collected, pelleted, and resuspended at 1 to $2 \times 10^{6} / \mathrm{mL}$ in 
Dulbecco's Modified Eagle Medium (Hazelton Biologics, Lenexa, KS) supplemented with $2.6 \times 10^{-2} \mathrm{M} \mathrm{NaHCO}_{3}, 1.8 \times 10^{-2}$ M 4-(2-hydroxyethyl-l-piperazine)-ethane sulfonic acid, $3 \times 10^{-5}$ $\mathrm{M}$ hypoxanthine, $3 \times 10^{-6} \mathrm{M}$ thymidine, $10^{-3}$ pyruvate, $5 \times$ $10^{-5} \mathrm{M}$ 2-mercaptoethanol, $10^{-4} \mathrm{M}$ minimal essential media nonessential amino acids (Hazelton Biologics), 15\% FCS and $10^{-6} \mathrm{M}$ hydrocortisone. Hydrocortisone was added to inhibit the formation of $\mathrm{T}$ cell colonies and to eliminate the effect of $\mathrm{T}$ lymphocytes (5). Additionally, CSF were added to the media in either of two ways: the IL-3/GM method or the IL-3/G method.

$I L-3 / G M$ method. Growth media was supplemented with 1000 $\mathrm{U} / \mathrm{mL}$ of IL-3 and $1000 \mathrm{U} / \mathrm{mL}$ of GM-CSF (both provided by Immunex Corp., Seattle, WA) and the cells were cultured in $24-$ well tissue culture plates (Costar, Cambridge, MA) at $37^{\circ} \mathrm{C}, 5 \%$ $\mathrm{CO}_{2}$. Growth media containing both IL-3 and GM-CSF was changed two times a week, and the cells were cultured continuously for $6 \mathrm{wk}$.

$I L-3 / G$ method. Growth media was supplemented only with $1000 \mathrm{U} / \mathrm{mL}$ of IL-3, and the cells were incubated for $2 \mathrm{~h}$ at $37^{\circ} \mathrm{C}$, $5 \% \mathrm{CO}_{2}$. After this incubation, the cells were washed once and transferred to growth media containing only $1000 \mathrm{U} / \mathrm{mL}$ of $\mathrm{G}$ CSF (Immunex Corp.). The cells were then transferred to 24well culture plates and kept at $37^{\circ} \mathrm{C}, 5 \% \mathrm{CO}_{2}$ for up to $4 \mathrm{wk}$, with two feedings of G-CSF supplemented growth media per week. The different CSF exposure sequence used in the IL-3/G cultures was adopted because preliminary studies showed that this sequence increased the percentages of PMN observed in cultures over continuous exposure to IL-3 plus G-CSF.

At weekly intervals, the contents of four to six culture wells were removed by gentle aspiration, washed once and processed as follows: 1) Aliquots were counted to estimate the total number of cells present in culture at each week, correcting for the number of wells harvested. 2) Aliquots were applied to microscope slides using a cytospin (Shandon Southern, Sewickley, PA) and stained by a modified Wright-Giemsa method (Diff-Quick; Scientific Products, McGaw Park, IL). Differential counts of 200 to 300 cells were performed on these slides. Promyelocytes were defined as cells ranging from 15 to $20 \mu \mathrm{m}$ in diameter with azurophilic granules in the cytoplasm. Myelocytes differed from promyelocytes by the appearance of specific granules and less prominence of the nucleoli. Metamyelocytes differed from myelocytes by the appearance of nuclear indentation. Bands were defined as cells with nuclear indentation of greater than $50 \%$; mature PMN were cells with the nucleus divided into lobes separated by thin filaments. 3) The chemotactic, phagocytic, and oxygen metabolic activities of in vitro propagated cells were compared with those of freshly purified peripheral blood PMN using the following assays: $a$ ) Chemotaxis assay. A rectangular trough, under-agarose assay was used as previously described (3). Troughs were filled with either $20 \mu \mathrm{L}$ of cultured cells $\left(2-5 \times 10^{7} / \mathrm{mL}\right)$ or purified blood PMN $\left(2-5 \times 10^{7} / \mathrm{mL}\right)$; AcS and $5 \times 10^{-7} \mathrm{M}$ fMLP were used as chemoattractant stimuli. The leading front distance (measured in $\mathrm{cm}$ on a projected image of the chemotaxis plate) was used as the parameter for movement. $b$ ) Phagocytosis assay. Boiled Saccharomyces cerevisiae were used as the phagocytic target. Either cultured cells or purified blood PMN were combined with yeast (ratio 1:100) and fresh human serum (10\% final) and were tumbled at $37^{\circ} \mathrm{C}$ for $15 \mathrm{~min}$. Aliquots of cells were then stained with trypan blue and examined microscopically (6). The percentage of cells containing $\geq 1$ unstained yeast was then determined based on counts of 100 to 200 cells. c) NBT reduction assay. Aliquots of either cultured cells or purified blood PMN were resuspended in $0.1 \%$ NBT (Sigma Chemical Co, St. Louis, MO) containing $20 \mathrm{ng} / \mathrm{mL}$ of PMA (Sigma Chemical Co.) and were incubated for $15 \mathrm{~min}$ at $37^{\circ} \mathrm{C}$. After this incubation, the cells were applied to a microscope slide using a cytospin and were counterstained with $0.25 \%$ safranine. The slides were then examined microscopically, and the percentage of cells stained with blue-purple formazan was calculated based on counts of 100 to 200 cells. 4) CD11b and CD15 surface antigen analysis was performed with a modified model no. $50 \mathrm{H}$ cytofluorograph (OrthoDiagnostics, Westwood, MA). Four different IL-3/G cultures (14-28 d old) were examined, using directly fluoresceinated Mo-1 (anti-CD1 1b) (Coulter Electronics, Hialeah, FL) and antiLeu M1 (anti-CD15) antibodies (Becton-Dickinson, Sunnyvale, CA). Fluoresceinated goat-anti-mouse IgM (Caltag Laboratories, So. San Francisco, CA) was used to label the anti-Leu M1 antibody in a second step. Fluoresceinated murine IgM and purified murine IgM were used as controls to determine background nonspecific binding of anti-CD1 $1 \mathrm{~b}$ and anti-CD15, respectively. A dextran sedimentation-purified, mixed leukocyte preparation from adult peripheral blood was used for comparison. Cell preparations were either held at $4^{\circ} \mathrm{C}$ or stimulated with $20 \mathrm{ng} / \mathrm{mL}$ of PMA at $37^{\circ} \mathrm{C}$ for $15 \mathrm{~min}$. After this, the cells were immediately chilled to $4^{\circ} \mathrm{C}$, washed, and antibody-stained for 30 min at each labeling step. The cytofluorographic analysis was then performed as previously described (7). 5) Aliquots were fixed in Karnovsky's fixative, rinsed in buffer, osmicated, dehydrated, embedded, sectioned, and examined by electron microscopy using standard methods (8). 6) Aliquots of cells were cryofixed using a CF-100 device (LifeCell Corp., Woodlands, TX), dried by molecular distillation (9), embedded, sectioned, and examined by electron microscopy. In some experiments, antigenic peroxidase was localized in cells prepared by this method using colloidal gold immunolocalization (9). In other experiments, colloidal gold conjugated soybean agglutinin (E-Y Laboratories, San Mateo, CA) was used to identify EOS at the electron microscopic level (10).

\section{RESULTS}

In Vitro Cultured Cell Numbers and Morphology. Both culture methods produced increasing total numbers of cells in vitro after the 1st wk of culture (Fig. 1). IL-3/GM cultures showed continuous increases in total cell number from wk 1 to 4 and a constant cell number from wk 4 to 6 . The cells present over the first $4 \mathrm{wk}$ in these cultures were a mixture of various differentiation levels of granulocytes (predominantly EOS), with the largest percentages of relatively mature (band forms + segmented forms) cells being present at 3 to $4 \mathrm{wk}$ (Table 1). After $4 \mathrm{wk}$, large histocytes, many containing phagocytized EOS, were the predominant remaining cell type.

IL-3/G cultures showed increasing cell numbers from wk 1 to 3 , with a decline in total cell numbers by wk 4 . A clear sequence of maturation of cells could be more easily seen in these cultures, with the percentages of mature PMN (band forms + segmented forms) being the highest at wk 2 and 3 . In these cultures, large phagocytic histocytes also became the prominent cell type beyond the $3 \mathrm{rd}$ wk of culture; therefore, the IL-3/G cultures were

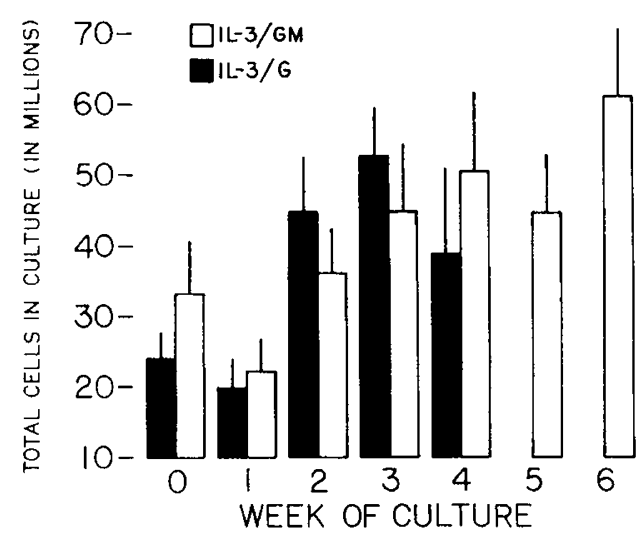

Fig. 1. Mean \pm SEM cell numbers present at each week in cultures of IL-3/G and IL-3/GM grown umbilical cord blood mononuclear cell fractions. Week 0 shows the number of nonadherent mononuclear cells placed in culture ( $n=6$ for IL-3/GM; $n=4-6$ for IL-3/G). 
Table 1. Mean \pm SEM percentages of mature cells in $I L-3 / G M$ and $I L-3 / G$ cultures by week

\begin{tabular}{|c|c|c|c|c|c|c|}
\hline & \multicolumn{6}{|c|}{ Week of culture } \\
\hline & 1 & 2 & 3 & 4 & 5 & 6 \\
\hline \multicolumn{7}{|l|}{ IL-3/GM method* } \\
\hline PMN bands + segmented & $17 \pm 6$ & $5 \pm 3$ & $6 \pm 3$ & $9 \pm 4$ & $19 \pm 7$ & $3 \pm 2$ \\
\hline \multicolumn{7}{|l|}{ IL-3/G method* } \\
\hline PMN bands + segmented & $5 \pm 1$ & $38 \pm 8$ & $56 \pm 6$ & $22 \pm 3$ & $\mathrm{ND}+$ & ND \\
\hline
\end{tabular}

$* n=6$.

$\dagger N D$, not determined.

not examined at the 5th and 6th wk as was done with the IL-3/ GM cultures.

In Vitro Cultured Cell Function. Chemotactic activity. IL-3/ GM grown cultures showed progressive increases in chemotactic activity to AcS and fMLP over the first 3 wk of culture (Fig. 2, left). Responsiveness to AcS was generally better than to fMLP, consistent with the EOS nature of the cells in these cultures (11), with the responsiveness to AcS at 2 and 3 wk of culture being no different than the AcS responsiveness of purified blood PMN. Responsiveness to AcS generally declined beyond the 5th wk of culture with IL-3/GM cells, whereas fMLP responsiveness was maximal at wk 3 and declined subsequently. Compared to historical umbilical cord blood PMN chemotactic responses (3), the IL-3/GM grown cells had better mean responses to AcS at all time points tested and the same mean responses to fMLP at the 2nd and 3rd wk of culture.

IL-3/G grown cultures (Fig. 2, right) showed progressive improvement in chemotactic responsiveness to both AcS and fMLP from wk 1 to 3 , with wk 4 values no different than those of wk 3. Chemotactic responsiveness to both fMLP and AcS was less than that observed with purified blood PMN at all time points examined. When compared with historical cord blood PMN chemotactic responses, mean responses of these cells to both AcS and fMLP were the same as the historical controls at wk 2 and 3.

Phagocytic activity. IL-3/GM cultures showed the largest percentages $(46 \pm 10 \%, n=5)$ of phagocytic cells at wk 1 , with a subsequent decrease to approximately $20 \%$ at wk 2 through 6 (Fig. 3). IL-3/G cultures, however, showed progressive increases

$$
I L-3 / G M
$$

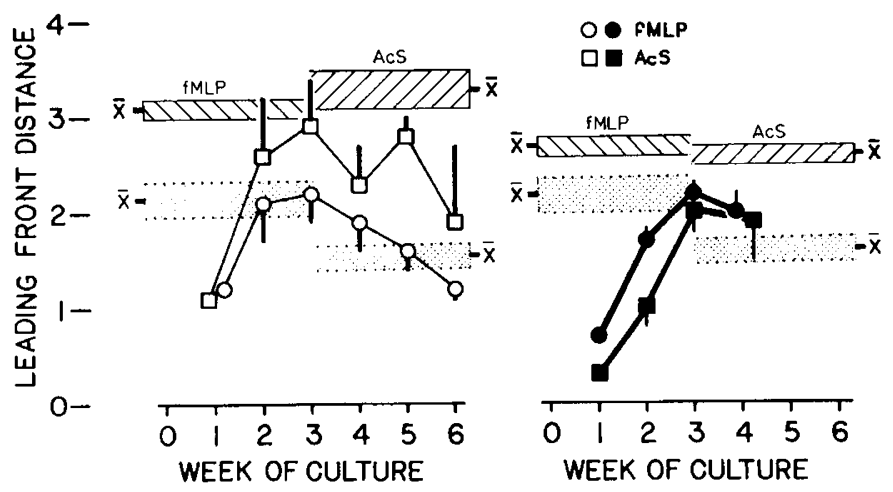

Fig. 2. Mean \pm SEM leading front distances observed when unfractionated cells from IL-3/GM (left) and IL-3/G (right) cultures were examined in an under-agarose chemotaxis assay $(n=2-5$ for both IL-3/ $\mathrm{GM}$ and IL-3/G). The chemoattractants used were $5 \times 10^{-7} \mathrm{M}$ fMLP and zymosan-activated serum. The upper hatched areas in each panel show the mean \pm SEM leading front values for adult blood PMN examined simultaneously. The lower stippled panels show the mean \pm SEM leading front values from 30 historical experiments using purified cord blood PMN (Reference 3).

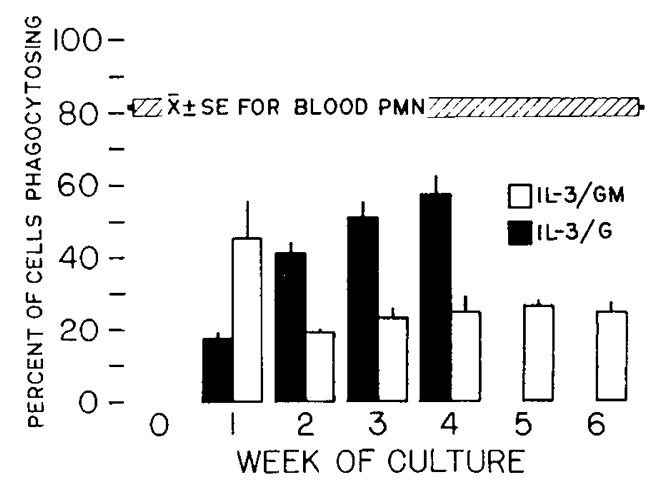

Fig. 3. Mean \pm SEM percentage of in vitro grown cells that phagocytose $S$. cerevisiae as a function of time in culture. The hatched area at the top shows the mean \pm SEM percentage of blood granulocytes that phagocytosed under the same conditions in simultaneously run control experiments ( $n=2-5$ for both IL-3/GM and IL-3/G).

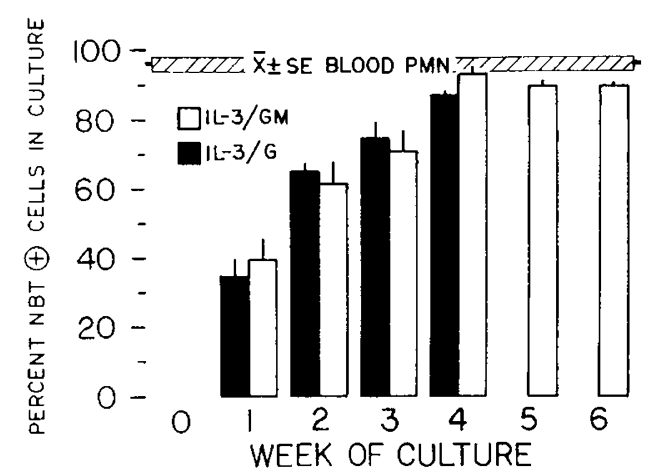

Fig. 4. Mean \pm SEM percentage of in vitro grown cells reducing NBT after stimulation with $20 \mathrm{ng} / \mathrm{mL}$ of PMA. The hatched area at the top shows the mean \pm SEM percentage of blood granulocytes reducing NBT under the same conditions in simultaneously run control experiments ( $n$ $=2-5$ for both IL-3/GM and IL-3/G).

in the percentage of phagocytic cells from wk 1 through 4, with $56 \pm 6 \%(n=4)$ of cells phagocytosing at $4 \mathrm{wk}$.

NBT reducing activity. IL-3/GM cultures showed continuously increasing percentages of NBT positive cells between wk 1 and 4 , reaching percentages no different from those observed with purified blood PMN $(96 \pm 2 \% n=5)$ at 4 wk of culture. At wk 5 and 6 of culture, approximately $90 \%$ of cells reduced NBT (Fig. 4). IL-3/G grown cultures also showed continuously increasing percentages of NBT + cells over wk 1 to 4 of culture. However, the percentages of NBT + cells observed at 4 wk $(87$ $\pm 1 \%, n=4)$ remained significantly lower than that observed with purified blood PMN $(p<0.001)$.

Surface Antigen Expression. CD1 $1 \mathrm{~b}$ and CD15 were chosen as surface antigens for these studies because the former begins to appear on the cell surface at the myelocyte stage (12), is heavily expressed on the fully mature granulocyte, and is upregulated by secondary granule secretagogue stimulation (13). The latter also 
begins to appear at the myelocyte stage (although slightly earlier than CD1 lb) (12), is expressed on greater than $95 \%$ of circulating granulocytes, and is variably upregulated by secondary granule secretagogue exposure (14). The peripheral blood mixed leukocyte preparation used as the control contained typical lymphocyte, monocyte, and granulocyte populations as defined by light scatter on the flow cytometer. The granulocyte population expressed both CD11b and CD15. CD11b was upregulated 3.7fold after PMA stimulation (Table 2) and CD15 expression increased 1.9-fold after stimulation. The CD11b +/CD15 + populations in all four of the cord cell cultures showed light scatter patterns different from the peripheral blood granulocyte population in the mixed leukocyte preparation. The CD11b +/ CD 15 + cord cells showed less side scatter than the blood neutrophils but slightly more forward scatter, suggesting decreased granularity and increased cell size (15). After PMA stimulation, cord blood granulocytes increased surface expression of CD $11 \mathrm{~b}$ an average of 2 -fold, whereas surface expression of CD15 did not change.

Ultrastructural Characteristics of In Vitro Grown Cells. With both culture methods, cells with the ultrastructural characteristics of all granulocyte maturational stages (16-18) (promyelocyte, myelocyte, metamyelocyte/band, segmented cell) were present and easily identified. Figure 5 illustrates these characteristics in both IL-3/GM and IL-3/G cultured cells. Early promyelocytes showed euchromatin $>$ heterochromatin, round-oval nuclei, nu-

Table 2. Surface expression and upregulation of CD11b and CD15 by IL-3/G grown cord blood cells

\begin{tabular}{|c|c|c|c|c|}
\hline & \multicolumn{4}{|c|}{ Mean fluorescence intensity } \\
\hline & \multicolumn{2}{|c|}{ CD1 lb } & \multicolumn{2}{|c|}{ CD15 } \\
\hline & Resting & Stimulated* & Resting & Stimulated \\
\hline \multicolumn{5}{|l|}{$\begin{array}{l}\text { Cord cell cul- } \\
\text { tures }\end{array}$} \\
\hline Culture A & 7.3 & 14.9 & 149.7 & 163 \\
\hline Culture B & 9.1 & 16.7 & 103.1 & 123.6 \\
\hline Culture C & 8.1 & 12.9 & 119.8 & 111.8 \\
\hline Culture D & 9.1 & 21.7 & 162.3 & 150.9 \\
\hline $\begin{array}{l}\text { Adult neutro- } \\
\text { phils }\end{array}$ & 14.5 & 54.3 & 160.5 & 309.7 \\
\hline
\end{tabular}

${ }^{*}$ Twenty $\mathrm{ng} / \mathrm{mL}$ PMA, $37^{\circ} \mathrm{C}, 15 \mathrm{~min}$.
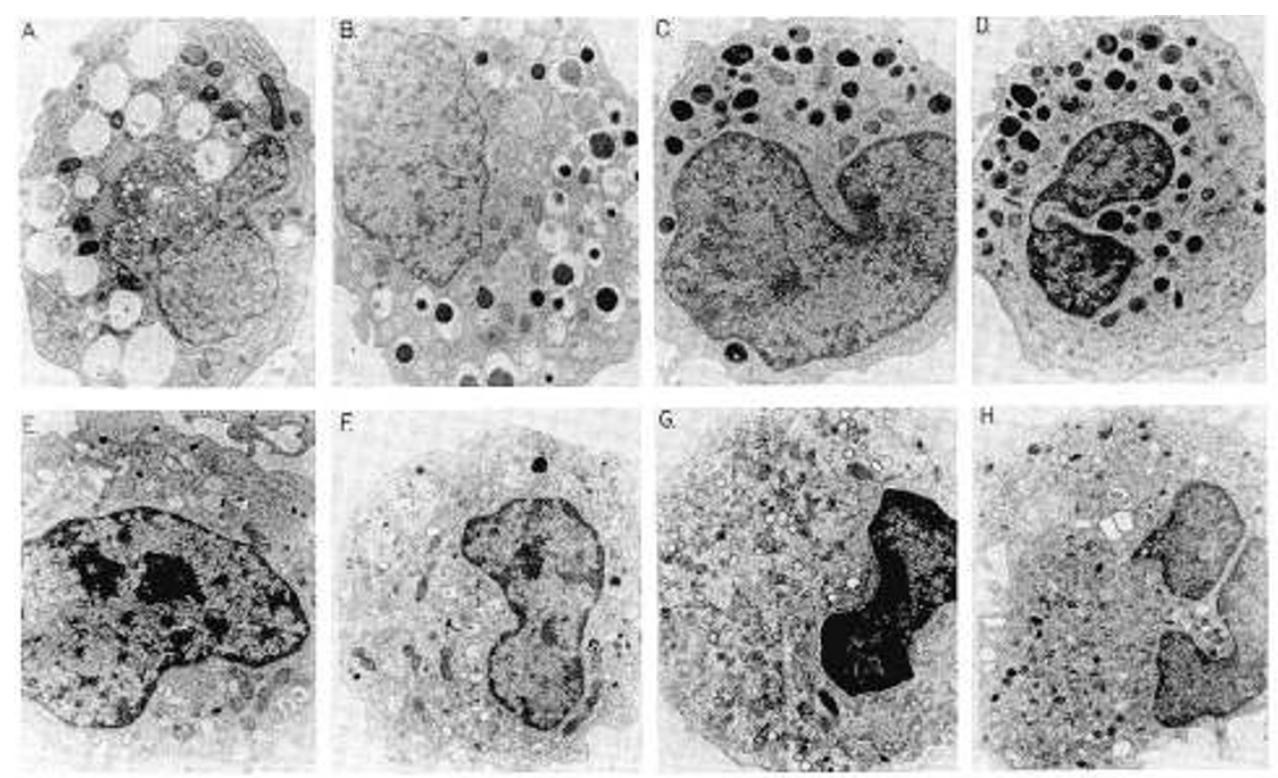

Fig. 5. Ultrastructural morphology of cells grown in vitro using IL-3/GM and IL-3/G methods. $A-D$, IL-3/GM grown promyelocyte, myelocyte, metamyelocyte band, and segmented cell, respectively. $E-H, \mathrm{IL}-3 / \mathrm{G}$ grown promyelocyte, myelocyte, metamyelocyte band, and segmented cell, respectively. 

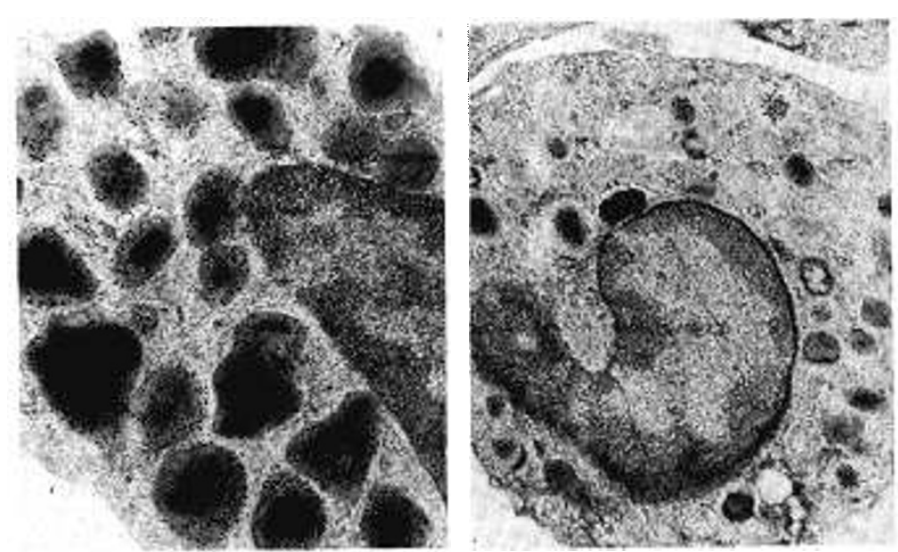

Fig. 6. Peripheral blood eosinophil (left) and IL-3/GM grown cell (right) labeled with colloidal gold conjugated soybean agglutinin.

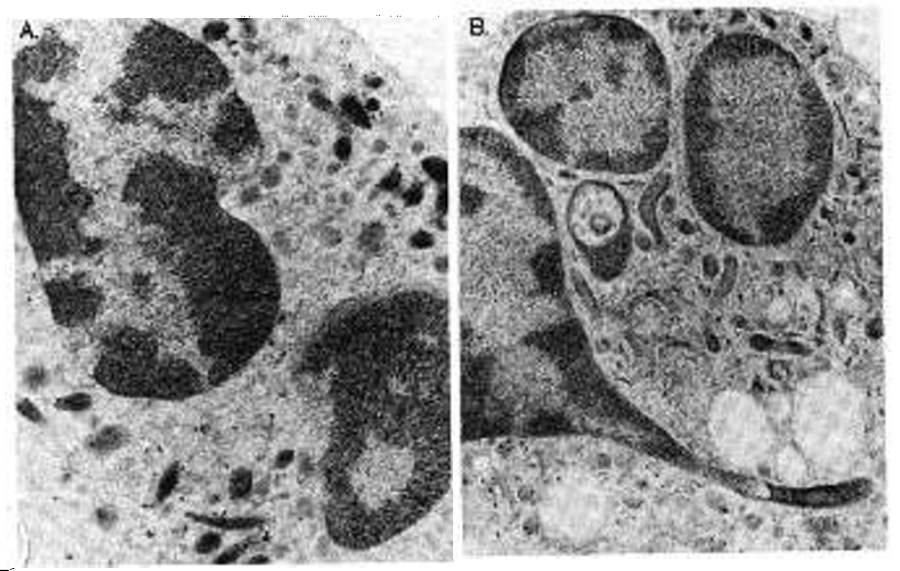

Fig. 7. Peripheral blood neutrophil $(A)$ and IL-3/G grown cell $(B)$ labeled with antimyeloperoxidase-biotinylated secondary antibody-streptavidin colloidal gold.

Myeloperoxidase, a recognized marker for the PMN primary granule, is present antigenically in a subpopulation of peripheral blood PMN intracellular granules (Fig. 7). When IL-3/G cells were similarly examined, antigenic peroxidase was present in cells as early as promyelocytes, and was also present in a subgroup of intracellular granules in the segmented, morphologically mature cells, identical to purified blood PMN (Fig. 7).

\section{DISCUSSION}

The purpose of these studies was to determine whether mature granulocytes could be cultivated in vitro from umbilical cord blood-derived myeloid progenitor cells in large enough numbers to examine their functional and morphologic characteristics. Physiologically normal granulocytes have previously been cultivated in small numbers using self-supporting, long-term in vitro cultures of human marrow without exogenous CSF additions (20). The cells produced were reported to have normal respiratory burst activity (NBT reduction/cytochrome $c$ reduction), hexose monophosphate shunt activity, phagocytosis, degranulation, and bactericidal activity. Small numbers of morphologically mature PMN have also been grown and differentiated in vitro, using enriched marrow myeloid progenitor preparations and exogenous additions of GM-CSF-containing culture supernates (21). These studies showed about a 3 -fold increase in the numbers of cells in culture over the first $6 \mathrm{~d}$, with a subsequent decline by $\mathrm{d}$ 10 , and these cells were used to examine the developmental acquisition of PMN membrane depolarization responses and intracellular calcium fluxes. Our method differs from these previous studies in that it uses an alternative source for the myeloid progenitor cells that is easily obtainable and inexhaustable, hu- man umbilical cord blood. It uses no special procedure to enrich for progenitor cells before culture, but does use defined amounts of specific recombinant CSF to stimulate both proliferation and differentiation. It produces greater yields of cells, which are large enough in number to permit functional testing, ultrastructural analysis, and surface antigen characterization. The cell types produced appear to be related to the specific CSF used (although this effect could also be due to the different exposure schedules used). Culture of cells with both IL-3 and GM-CSF present continuously results in predominantly EOS proliferation and differentiation with relatively few PMN. Proliferation is demonstrated by increases in cultured cell numbers over the first $4 \mathrm{wk}$. Differentiation is demonstrated by progressive increases in the percentage of mature (bands + segments) forms over time and progressive increases in two maturation-related functional capabilities, stimulated respiratory burst activity and chemotactic responsiveness (22-25). Notable for its lack of development over time was phagocytic activity in the IL-3/GM grown cells. Although at first surprising, this pattern of functional development is, in fact, consistent with the presence of differentiating EOS in the IL-3/GM cultures. Eosinophils have active respiratory burst activity (26) and respond chemotactically to AcS but not to fMLP (27). They are also less phagocytically active than PMN (28).

When cells are briefly exposed to IL-3, followed by continuous exposure to only G-CSF, PMN proliferation and differentiation occurs. In these cultures, cell numbers increase over time, as does the percentage of mature (bands + segments) PMN, with essentially no EOS proliferation. IL-3/G grown cells show progressive increases in all three of the functional activities examined (stimulated respiratory burst activity, chemotactic responsiveness, and phagocytic activity), which clearly demonstrates that differentiation is occurring in these in vitro grown cells. Despite the differentiation, however, the NBT reduction, phagocytic, and locomotive activities of these cells are never equivalent to those of purified blood neutrophils; neither is the ability of the cells to up-regulate surface CD 11 b and CD 15 antigens after PMA stimulation. This apparent lack of functional equality between in vitro and in vivo grown PMN could possibly be explained in several ways.

Our in vitro grown cell preparations are mixtures of cells at various maturational stages (Table 1), and, because we examined maturation-related functional activities, lack of equality with purified mature cell preparations is probably appropriate. Secondly, mature neutrophils purified from marrow are not the functional equals of mature neutrophils purified from blood with respect to their respiratory burst activity, locomotive capabilities, phagocytic activity, and alkaline phosphatase content (29-34) The lower respiratory burst, phagocytosis, and chemotaxis responses observed with our in vitro grown cells, therefore, may be appropriately normal for cells that would be equivalent to marrow PMN. Thirdly, neonatal human PMN are known to have depressed chemotactic responses compared with adult human PMN, but equal respiratory burst and phagocytic activity (3). The granulocytes produced in vitro by our method are the progeny of umbilical cord blood derived cells, and it is possible that myeloid progenitors from umbilical cord blood give rise to functional "neonatal" PMN. We think that the demonstration of locomotive responses that are equal to or superior to historical cord blood PMN responses, using mixed in vitro grown cell preparations, is against this explanation. Clear demonstration of this awaits the direct functional comparison of purified, mature, in vitro grown cells with purified adult and cord blood PMN. Lastly, it is possible that in vitro granulocyte differentiation using our IL-3/G or IL-3/GM methods lacks an additional biologic factor or condition that is necessary for complete terminal differentiation of granulocytic cells. We feel that this explanation is most likely and are currently examining whether other exposures will enhance terminal differentiation in this system.

Ultrastructurally, cells with all of the classical morphologic 
details of promyelocytes, myelocytes, metamyelocytes, bands, and segmented cells could be found in our cultures, confirming that differentiation was occurring. In the EOS, intracellular granules appeared to form in a single intracellular structure (35), and most of their granules demonstrated strong soybean agglutinin staining. The PMN nature of IL-3/G grown cells could not be so definitively demonstrated by ultrastructural antigen localization. However, these cells had only rare soybean agglutinin positive granules, and antigenic peroxidase first appeared in granules within cells with the morphologic characteristics of promyelocytes, consistent with their being PMN.

In summary, we have demonstrated that either PMN or EOS can be grown in vitro from umbilical cord blood derived myeloid progenitors. The cells can be grown in numbers adequate to examine their function and morphology, revealing that both in vitro grown PMN and EOS develop some of the functional characteristics of peripheral blood PMN. Morphologically, these cultures contain all of the maturational stages of PMN or EOS.

In vitro cultivation of umbilical cord blood myeloid progenitor cells in a liquid culture system, using recombinant CSF, is an easy and efficient model system with which multiple aspects of granulocyte structure and function can be studied.

Acknowledgments. The authors thank Immunex Corp., Seattle, WA, for supplying the recombinant IL-3, GM-CSF, and G-CSF used in these studies; Saroj Vadhan-Raj, M.D., for her support and encouragement; and Anne Wright for her excellent word processing and editorial skills.

\section{REFERENCES}

1. Christensen RD 1987 Clinical and laboratory observations: circulating pluripotent hematopoietic progenitor cells in neonates. J Pediatr 110:622-625

2. Broxmeyer HE, Douglas GW, Hangoc G, Cooper S, Bond J, English D, Arny M, Thomas L, Boyle EA 1989 Human umbilical cord blood as a potential source of transplantable hematopoietic stem/progenitor cells. Proc Natl Acad Sci USA 86:3828-3832

3. Frenck RW, Buescher ES, Vadhan-Raj S 1989 The effects of recombinant human granulocyte-macrophage colony stimulating factor on in vitro cord blood granulocyte function. Pediatr Res 26:43-48

4. Ventura GJ, Hester JP, Buescher ES, Vadhan-Raj S, Durrett A, Reading CL 1990 Hematopoiesis in limiting dilution cultures: influence of cytokines on human hematopoietic progenitor cells. Exp Hematol 18:878-882

5. Takaue Y, Reading CL, Roome AJ, Dicke KA, Tindle S, Chandran M, DeVaraj B 1987 Limiting dilution analysis of the effects of colony stimulating factors, phytohemagglutinin and hydrocortisone on hematopoietic progenitor cell growth. Blood 70:1611-1618

6. Patterson-Delafield J, Lehrer RI 1977 A simple microscopic method for identifying and quantitating phagocytic cells in vitro. J Immunol Methods 18:377-379

7. Mirro J, Zipf TF, Pui C-H, Kitchingman G, Williams D, Melvin S, Murphy S, Stass S 1985 Acute mixed lineage leukemia: clinicopathologic correlations and prognostic significance. Blood 66:1115-1123

8. VanWinkle WB, Schwartz A 1978 Morphological and biochemical correlates of skeletal muscle contractility in the cat: histochemical and electron microscopic studies. J Cell Physiol 97:99-120

9. Livesey SA, Buescher ES, Krannig GL, Harrison DS, Linner JG, Chiovetti R 1989 Human neutrophil granule heterogeneity: immunolocalization studies using cryofixed, dried and embedded specimens. Scanning Microsc 3(suppl):231-240

10. Eguchi M, Ozawa T, Suda J, Sugita K, Furukawa T 1989 Lectins for electron microscopic distinction of eosinophils from other blood cells. J Histochem Cytochem 37:743-749

11. Ogawa H, Kunkel SL, Fantone JC, Ward PA 1981 Comparative study of eosinophil and neutrophil chemotaxis and enzyme release. Am J Pathol 105:149-155
12. Civin CI 1990 Human monomyeloid cell membrane antigens. Exp Hematol 18:461-467

13. Buescher ES, Gaither T, Nath J, Gallin JI 1985 Abnormal adherence-related functions of neutrophils, monocytes and Epstein-Barr virus-transformed B cells in a patient with C3bi receptor deficiency. Blood 65:1382-1390

14. Tetteroo PAT, Visser FJ, Bos MJE, Guerts van Kessel AHM, Tromp JF, von dem Borne 1984 Serological, biochemical and cytogenic studies with the granulocyte monoclonal antibodies of the "M protocol". In: Reinherz, EL, Haynes BF, Nadler LM, Bernstein ID, (eds) Leukocyte Typing II, Vol 3. Springer-Verlag, New York, pp 28-45

15. Fletcher MP, Seligmann BE 1985 Monitoring human neutrophil secretion by flow cytometry; secretion and membrane potential changes assessed by light scatter and a fluorescent probe of membrane potential. $\mathbf{J}$ Leukocyte Bio $37: 431-447$

16. Brederoo P, van der Meulen J, Daems WT 1986 Ultrastructural localization of peroxidase activity in developing neutrophil granulocytes from human bone marrow. Histochemistry 84:445-453

17. Miller F, DeHarven E, Palade GE 1966 The structure of eosinophil leukocyte granules in rodents and in man. J Cell Biol 31:349-362

18. Bainton DF, Farquhar MG 1970 Segregation and packaging of granule enzymes in eosinophilic leukocytes. J Cell Biol 45:54-73

19. Bainton DF, Ullyot JL, Farquhar MG 1971 The development of neutrophilic polymorphonuclear leukocytes in human bone marrow: origin and content of azurophil and specific granules. J Exp Med 134:907-934

20. Greenberg HM, Newberger PE, Parker LM, Novak T, Greenberger JS 198 Human granulocytes generated in continuous bone marrow culture are physiologically normal. Blood 58:724-732

21. Sullivan R, Melnick DA, Malech HL, Meshulam T, Simons ER, Lazzari KG, Proto PJ, Gadenne A-S, Leavitt JL, Griffin JD 1987 The effects of phorbol myristate acetate and chemotactic peptide on transmembrane potentials and cytosolic free calcium in mature granulocytes evolve sequentially as the cells differentiate. J Biol Chem 262:1274-1281

22. Wallace PJ, Packman CH, Lichtman MA 1987 Maturation-associated changes in the peripheral cytoplasm of human neutrophils: a review. Exp Hematol 15:34-45

23. Glasser L, Fiederlein RL 1987 Functional differentiation of normal human neutrophils. Blood 69:937-944

24. Zakhireh B, Root RK 1979 Development of oxidase activity by human bone marrow granulocytes. Blood 54:429-439

25. Fontana JA, Wright DG, Schiffman E, Corcoran BA, Deissreoth AB 1980 Development of chemotactic responsiveness in myeloid precursor cells: studies with a human leukemia cell line. Proc Natl Acad Sci USA 77:36643668

26. Weiss SJ, Test ST, Eckmann CM, Roos D, Regiani S 1986 Brominating oxidants generated by human eosinophils. Science $234: 20-23$

27. Bass DA, Grover WH, Lewis JC, Szejda P, DeChatelet LR, McCall CE 1980 Comparisons of human eosinophils from normals and patients with eosinophilia. J Clin Invest 66:1265-1273

28. Cline MJ, Hanifin J, Lehrer RI 1968 Phagocytosis by human eosinophils. Blood 32:922-934

29. Hetherington SV, Quie PG 1985 Human polymorphonuclear leukocytes of the bone marrow, circulation, and marginated pool: function and granule protein content. Am J Hematol 20:235-246

30. Altman AJ, Stossel TP 1974 Functional immaturity of bone marrow bands and polymorphonuclear leukocytes. Br J Haematol 27:241-245

31. Berkow RL, Dodson RW 1986 Purification and functional evaluation of mature neutrophils from human bone marrow. Blood 68:853-860

32. Evans WH, Wilson SM, Bednarek JM, Peterson EA, Knight RD, Mage MG, McHugh L 1989 Evidence for a factor in normal human serum that induces human neutrophilic granulocyte end-stage maturation in vitro. Leuk Res 13:673-682

33. Sato N, Asana S, Urabe A, Ohsawa N, Takaku F 1985 Induction of alkaline phosphatase in neutrophilic granulocytes, a marker of cell activity, from bone marrow of normal individuals by retinoic acid. Biochem Biophys Res Comm 131:1181-1186

34. Fehr J, Grossmann HC 1979 Disparity between circulating and marginated neutrophils: evidence from studies on the granulocyte alkaline phosphatase, a marker of cell maturity. Am J Hematol 7:369-379

35. VanWinkle WB, Frenck RW, Vadhan-Raj S, Buescher ES 1990 The eosinophil promyelocyte vesiculum: an alternate pathway of granulogenesis in the presence of colony stimulating factors in vitro and in vitro. J Cell Biol 111:309A (abstr 1722) 